\title{
Natural history of herpes zoster ophthalmicus: predictors of postherpetic neuralgia and ocular involvement
}

\author{
S P HARDING,' J R LIPTON,' AND J C D WELLS \\ From 'St Paul's Eye Hospital and 'Walton Hospital, Liverpool
}

SUMMARY Seventy-one patients presenting with acute herpes zoster ophthalmicus were followed up for six months for a prospective analysis of the natural history of the disease. Acute and chronic ocular complications, nasociliary nerve involvement, age, sex, rash, and pain were assessed, and the results are presented. Acute pain was measured by a visual analogue scale. Postherpetic neuralgia (PHN) was more likely in patients over 80 and in those who scored their pain highly at presentation. Duration of rash was longer in patients who developed PHN. No other associations between the parameters studied were found. Nasociliary nerve involvement was associated with subsequent ocular disease.

Ophthalmic involvement has been considered the most important and potentially serious of all sites for herpes zoster. It is reported as occuring in $33^{1}$ to $50 \%^{2}$ of cases and has the highest incidence of postherpetic neuralgia (PHN). ${ }^{3}$ As a result it is the site that most often requires treatment, and this is usually prolonged.

A number of retrospective studies have looked at the natural history of herpes zoster. deMoragas and Kierland $^{3}$ reviewed 916 cases, of which $149(16 \cdot 3 \%)$ were trigeminal. Burgoon et al.' reviewed 206 cases, of which $36(17 \cdot 5 \%)$ were ophthalmic. Both reported a higher incidence of complications in trigeminal involvement than elsewhere. Leisegang ${ }^{4}$ and Womack and Leisegang' have more recently reviewed respectively 94 and 86 patients with acute herpes zoster for ocular complications.

This study we believe for the first time prospectively analyses the natural history of acute herpes zoster ophthalmicus. In view of their high incidence and morbidity we have in addition looked for predictive indicators of ocular involvement and PHN in order to allow early identification and treatment of those patients most at risk.

\section{Patients and methods}

Between January and August 198453 patients presenting to the Accident and Emergency Department

Correspondence to Mr S P Harding. St Paul's Eyc Hospital, Old Hall Street, Liverpool L3 9PF. of St Paul's Eye Hospital, Liverpool, with acute herpes zoster ophthalmicus were examined. In addition a further 25 patients were examined at Manchester Royal Eye Hospital in the same period. Seven patients were excluded, four at Liverpool and three at Manchester: three patients could not understand standardised questions; two were taking homoeopathy at the time of presentation, rendering analysis of subsequent progression potentially unreliable; one died of an unrelated cause; one was admitted to another hospital and lost to follow-up. A total of 71 patients were studied.

Standardised assessment forms were completed at presentation and at subsequent visits. Pain was assessed by visual analogue scale (VAS). The patient was asked to look at a $100 \mathrm{~mm}$ horizontal line with a zero at one end and three pluses at the other, with the instruction that the latter represented the worst pain he could possibly imagine. He was then asked to indicate with a mark along the line the severity of any pain being experienced at the time of the interview, and a measurement was taken in millimeters. At subsequent interviews a fresh line was presented. Ocular involvement, nasociliary nerve (NCN) involvement at presentation, rash severity, and duration were also assessed.

Assessment of pain by a VAS has been shown to be reproducible for the same individual and a method that allows reliable statistical analysis. " Like all pain assessment it is subjective, and hence direct comparisons between patients cannot be made. However, 
Fig. 1 Age distribution of 71 cases of herpes zoster ophthalmicus compared with local population characteristics.

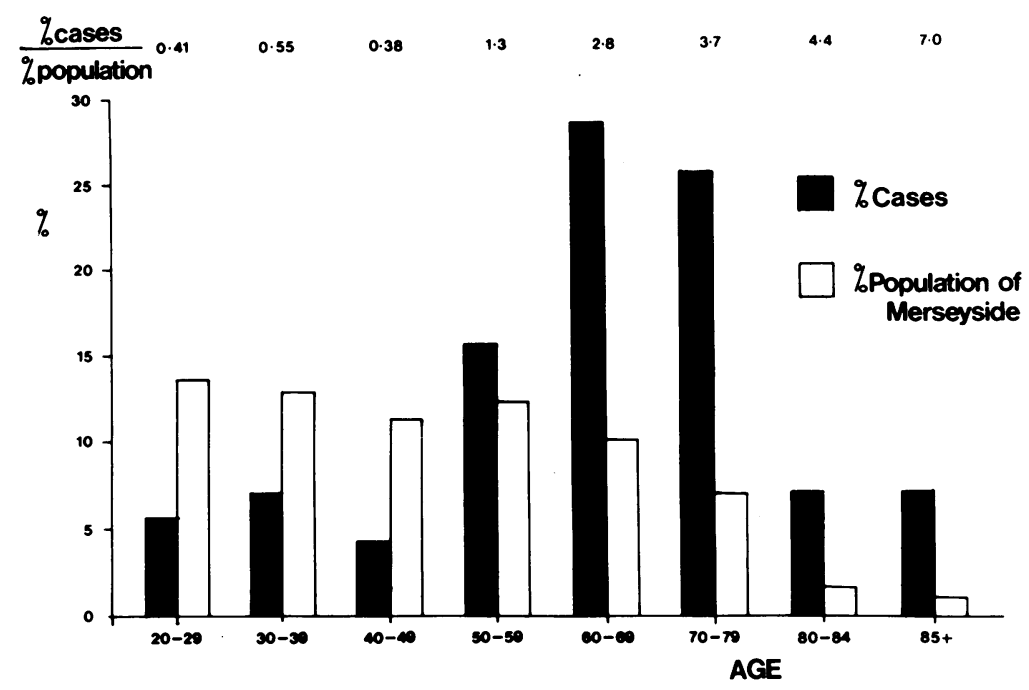

analysis of longitudinal changes in pain for an individual are statistically valid.

After initial assessment 15 randomly allocated patients aged 60 and over were separately studied in an analysis of stellate ganglion blockade, the results of which are reported elsewhere. ${ }^{7}$ The remaining 56 patients were followed up for six months. Ocular complications and pain were treated on their merits. PHN was defined as the presence of continuous or frequent pain at or after six months.

\section{Results}

The findings in 71 patients presenting with acute herpes zoster ophthalmicus were statistically analysed (Table 1 ). Mean age was 63.2 years $(S D=$ 16.64); range was 23-92.

Age distribution analysis (Fig. 1) showed a peak frequency from 60 to 69 years, but correction for local population characteristics indicated a steady rise in frequency with age. The sex distribution is also shown in Table 1 . There was a highly significant predominance of male patients under 60 years old $\left(\chi_{y}^{2}=7 \cdot 144 ; p<0 \cdot 01\right) ;$ this was more pronounced under 40 years $\left(\chi_{y}^{2}=9.690 ; p<0.01\right)$ (the y denotes that Yates's correction was applied).

Thirteen patients were pain free at presentation $(18 \cdot 3 \%)$. No patients had malignant disease at presentation or during subsequent follow-up. The ocular complications noted in 71 patients excluding conjunctivitis are listed in Table 2 . One patient developed contralateral disease with rash three months after initial presentation; at that time there was active keratouveitis on the initially affected side but no subsequent involvement of the fellow eye occurred.

Fifteen patients aged 60 and over, randomly allocated at presentation to treatment with stellate ganglion block were then excluded, and analysis of the remaining 56 is presented below.

\section{OCULAR INVOLVEMENT}

Twenty-eight of 56 patients developed ocular complications $(50 \%)$. The mean time of onset was 1.82 weeks after the onset of the rash, with a range of one to four weeks. When related to age (Table 1) there

Table 1 Factors associated with herpes zoster ophthalmicus compared with age

\begin{tabular}{|c|c|c|c|c|c|c|c|c|c|c|c|c|c|c|c|}
\hline \multirow[t]{2}{*}{ Age } & \multirow{2}{*}{$\begin{array}{l}\text { Overall } \\
\text { group }\end{array}$} & \multicolumn{2}{|c|}{ Sex } & \multirow{2}{*}{$\begin{array}{l}\text { Untreated } \\
\text { group }\end{array}$} & \multicolumn{4}{|c|}{ Ocular involvement } & \multicolumn{2}{|l|}{ Rash } & \multicolumn{3}{|c|}{ Acute pain (mean VAS) } & \multicolumn{2}{|c|}{ PHN } \\
\hline & & $M$ & $F$ & & + & - & $\begin{array}{l}\text { Mean } \\
\text { onset } \\
\text { (weeks) }\end{array}$ & Chronic & $\begin{array}{l}\text { Mean } \\
\text { severity }\end{array}$ & $\begin{array}{l}\text { Mean } \\
\text { duration } \\
\text { (days) }\end{array}$ & $\begin{array}{l}\text { Presen- } \\
\text { tation }\end{array}$ & $2 / 52-1 / 12$ & $10 / 52-3 / 12$ & + & - \\
\hline $20-39$ & 9 & 8 & 1 & 9 & 6 & 3 & $1 \cdot(0)$ & () & $2 \cdot 22$ & $17 \cdot 56$ & 38.89 & $8 \cdot 72$ & $4 \cdot 33$ & 1 & 8 \\
\hline $40-59$ & 14 & 6 & 8 & 14 & 4 & 10 & $1 \cdot 25$ & 1 & 1.71 & 20.78 & $36 \cdot 50$ & $20 \cdot 08$ & $5 \cdot 62$ & $i$ & 13 \\
\hline $60-79$ & 38 & 10 & 28 & 26 & 12 & 14 & $2 \cdot 25$ & 6 & $1 \cdot 89$ & $23 \cdot 62$ & $37 \cdot 69$ & $31 \cdot 67$ & $20 \cdot 83$ & 5 & 21 \\
\hline $80+$ & 10 & 2 & 8 & 7 & 6 & 1 & $2 \cdot 17$ & 1 & $2 \cdot 29$ & $24 \cdot 71$ & $37 \cdot(x)$ & $31 \cdot 58$ & $34 \cdot 75$ & 5 & 2 \\
\hline Total & 71 & 26 & 45 & 56 & 28 & 28 & & 8 & & & & & & 12 & 44 \\
\hline
\end{tabular}


Table 2 Nature of ocular complications in 71 patients

\begin{tabular}{lr}
\hline Anterior uveitis & 33 \\
Keratitis & 16 \\
$\quad$ Disciform keratitis & 9 \\
Neuropathic corncal ulcer & 3 \\
Secondary glaucoma & 2 \\
Cranial nerve palsy & 2 \\
$\quad$ IVth nerve & 1 \\
VIth nerve & 1 \\
Contralateral herpes zoster ophthalmicus & 1 \\
Orbital apex syndrome & 1 \\
Total involved & 36 \\
\hline
\end{tabular}

was a difference in mean time of onset of involvement between those under $60(1.10$ weeks) and those aged 60 and over $(2 \cdot 23$ weeks $)$, and this achieved a high level of significance $(t=9 \cdot 379 ; p \ll<0.001)$. There was no significant difference in incidence of ocular involvement in relation to age: under 40 compared with over $40\left(\chi_{y}^{2}=0.530 ; p>0 \cdot 1\right)$; under 60 with over $60\left(\chi_{y}^{2}=0 \cdot 295 ; p>0 \cdot 5\right)$; under 80 with over $80\left(\chi_{y}^{2}=\right.$ $2 \cdot 613 ; p>0 \cdot 1)$. There was no significant difference in incidence of ocular involvement between the sexes $\left(\chi_{y}^{i}=0\right)$ (Table 3$)$.

Treatment of keratitis and uveitis was initially with acyclovir ointment, and topical steroids were introduced only later in severe unresponsive cases and in several of those which went on to chronicity.

Ocular involvement when still active at six months was defined as chronic and occurred in eight of 28 initially involved patients $(28.6 \%)$. Chronic eye disease occurred in $14.3 \%$ of the 56 patients studied, with an age range of 54-91. However, the difference in incidence between those under 54 and those aged 54 and over did not achieve significance $\left(\chi_{y}^{i}=2 \cdot 734\right.$ $p>0 \cdot 05)$. Seven patients had keratouveitis still active at six months, two of these with an associated secondary glaucoma; a further three had neuropathic corneal ulcers. All had chronic anterior uveitis.

\section{NASOCILIARY NERVE}

$\mathrm{NCN}$ involvement was assessed at presentation and was defined as involvement by rash of the external nasal nerve. It occurred in 21 of 56 patients $(37 \cdot 5 \%)$. There was a highly significant association between presence of NCN involvement at presentation and the subsequent development of ocular complications

Table 3 Factors related to ocular involvement

\begin{tabular}{|c|c|c|c|c|c|c|c|}
\hline \multirow{2}{*}{$\begin{array}{l}\text { Ocular } \\
\text { involvement }\end{array}$} & \multicolumn{2}{|c|}{ Sex } & \multicolumn{2}{|c|}{$N C N$} & \multirow{2}{*}{$\begin{array}{l}\text { Mean } \\
\text { rash } \\
\text { severity }\end{array}$} & \multicolumn{2}{|c|}{$P H N$} \\
\hline & $M$ & $F$ & + & - & & + & - \\
\hline+ & 13 & 15 & 16 & 12 & $2 \cdot() 4$ & 7 & 21 \\
\hline- & 12 & 16 & 5 & 23 & $1 \cdot 86$ & 5 & 23 \\
\hline
\end{tabular}

$\left(\chi_{\bar{y}}^{\prime}=7 \cdot 619 ; p<0 \cdot 01\right)$ (Table 3). If NCN involvement existed at presentation, there was a $76.2 \%$ chance of subsequent ocular involvement. If there was no NCN involvement at presentation, there was only a $34.3 \%$ chance of the eye developing complications.

There was no significant association between NCN involvement and chronicity of ocular complications in already involved eyes $\left(\chi_{y}^{2}=0 \cdot 616 ; p>0 \cdot 1\right)$.

RASH

Severity of rash was estimated on a 1-3 scale, 1 representing mild, 2 moderate, and 3 severe. There was no significant difference between severity of rash and age: under 40 compared with 40 and over $(t=1.365 ; \mathrm{p}>0 \cdot 1)$ (Table 1$)$. There was no significant difference between rash severity in patients who went on to develop ocular involvement compared with those who did not $(t=0 \cdot 924 ; \mathrm{p}>0 \cdot 1)$. (Table 3$)$.

Duration of rash was measured by duration of crusts in days, with a mean of 22.0 days and a range of 6-35 days. The mean duration of rash in each age group (Table 1) increased with age. Patients under 40 had a significantly shorter duration of rash than those aged 40 and over $(t=2 \cdot 292 ; p<0 \cdot 05)$, and this held for those aged under 60 and 60 and over $(t=2 \cdot 489$; $\mathrm{p}<0 \cdot 02)$.

\section{PAIN}

Ten patients out of 56 were pain free at presentation $(18 \%)$. Six of these developed pain at some time later $(60 \%)$ and two of these went on to develop PHN. Four of the 56 patients $(7 \%)$ were pain free throughout the course of the disease.

Table 1 shows the mean VAS scores at presentation and during subsequent time bands for each of four age groups. For the 20-39 age group the mean VAS scores fell dramatically by two weeks to one month $(p<0.01)$, while this fall had occurred only by six weeks to three months for the $40-59$ age group $(p<0 \cdot 01)$. For the 60-79 age group there was a fall in mean VAS by six weeks to three months, but this was of lesser significance $(p<0 \cdot 05)$. For the patients aged 80 and over there was no significant fall at any time during the acute phase $(\mathrm{p}>0 \cdot 05)$.

An analysis was performed by comparing pain scores at presentation with those in subsequent time bands within each group by paired $t$ tests.

Table 4 shows that compared with presentation there was a fall in incidence of pain at each subsequent time band. This achieves significance by six weeks to three months $\left(\chi_{y}^{2}=12.72 ; p<0.001\right)$ and is very highly significant by six months $\left(\chi_{y}^{2}=41 \cdot 34\right.$; $\mathrm{p} \ll<0.001)$.

\section{POSTHERPETIC NEURALGIA}

Twelve of the 56 patients developed PHN (21\%). 
Table 4 Factors related to the development of postherpetic neuralgia

\begin{tabular}{|c|c|c|c|c|c|c|c|c|c|c|c|}
\hline \multirow[t]{3}{*}{$P H N$} & \multicolumn{2}{|l|}{ Sex } & \multirow{3}{*}{\multicolumn{2}{|c|}{$\begin{array}{l}\text { Chroniceye } \\
\text { disease } \\
+\end{array}$}} & \multicolumn{2}{|c|}{$N C N$} & \multicolumn{2}{|l|}{ Rash } & \multirow{3}{*}{$\begin{array}{l}\text { Mean onset } \\
\text { ocular } \\
\text { involvement } \\
\text { (weeks) }\end{array}$} & \multirow{2}{*}{\multicolumn{2}{|c|}{$\begin{array}{l}\text { Mean VAS at } \\
\text { presentation }\end{array}$}} \\
\hline & \multirow[t]{2}{*}{$M$} & \multirow[t]{2}{*}{$F$} & & & \multirow[t]{2}{*}{+} & \multirow[t]{2}{*}{-} & \multirow{2}{*}{$\begin{array}{l}\text { Mean } \\
\text { severity }\end{array}$} & \multirow{2}{*}{$\begin{array}{l}\text { Mean } \\
\text { duration } \\
\text { (days) }\end{array}$} & & & \\
\hline & & & & & & & & & & All ages & Over 60 \\
\hline+ & 5 & 7 & 2 & 5 & 2 & 10 & $2 \cdot 17$ & $25 \cdot 08$ & $2 \cdot 20$ & $47 \cdot 42$ & $53 \cdot 10$ \\
\hline- & 20 & 24 & 6 & 15 & 19 & 25 & $1 \cdot 88$ & $21 \cdot 25$ & $1 \cdot 71$ & $34 \cdot 80$ & 30.78 \\
\hline
\end{tabular}

Factors that might influence or be associated with this development were sought.

Age. The mean age for those patients who developed PHN was $70 \cdot 75$ years (range $25-92$ ). This was significantly higher than those who did not58.34 years $(t=2 \cdot 242 ; \mathrm{p}<0 \cdot 05)$. Table 1 shows the incidence of PHN related to age. $30 \%$ of patients aged 60 and over were afflicted, while the incidence rose to $71 \%$ at 80 and over. There was a highly significant difference in incidence of PHN between patients under 80 and those 80 and over $\left(\chi_{y}^{2}=8.727\right.$; $p<0 \cdot 01)$, but a significant difference did not occur at lower ages.

Sex. There was no significant difference in incidence of PHN between the sexes $\left(\chi_{y}^{2}=0.0088\right.$ $p>0.05)$. This non-significance did not change when only patients over 60 were analysed $\left(\chi_{y}^{2}=0.01\right.$; $\mathrm{p}>0.5$ ) (Table 4).

Ocular involvement. This was not significantly associated with PHN $\left(\chi_{\mathrm{y}}^{2}=0.002 ; \mathrm{p}>0.5\right)$ (Table 3$)$. PHN was not associated with chronic eye disease $\left(\chi_{y}^{2}=0.001 ; p>0.5\right)$ (Table 4). Mean time of onset of ocular involvement after onset of rash was greater in those who developed PHN, but this did not achieve significance $(t=0.962 ; \mathrm{p}>0 \cdot 1)$.

Nasociliary nerve involvement. This was not associated with subsequent development of PHN $\left(\chi_{y}^{2}=1 \cdot 576 ; p>0 \cdot 1\right)$ (Table 4).

Rash. Duration of rash was longer in those patients who developed PHN but this was not significant $(t=1.793 ; \mathrm{p}>0.05)$ (Table 4$)$. Severity of rash was greater in those who developed PHN but was also not significant $(t=1 \cdot 195 ; \mathrm{p}>0 \cdot 1)$.

Acute pain. Mean VAS scores at presentation were higher in those patients who subsequently developed PHN (Table 4). This was significant for patients aged 60 and over $(t=2 \cdot 204 ; \mathrm{p}<0.05)$ but not for the whole group $(t=1 \cdot 402 ; \mathrm{p}>0 \cdot 1)$. However, VAS scores of 35 $\mathrm{mm}$ and over at presentation were significantly associated with PHN when compared with scores below $35 \mathrm{~mm}\left(\chi_{y}^{2}=5 \cdot 197 ; p<0 \cdot 05\right)$. This was also true of comparisons between scores of under $30 \mathrm{~mm}$ and those of $30 \mathrm{~mm}$ and over $\left(\chi_{\mathrm{y}}^{2}=4.023 ; \mathrm{p}<0.05\right)$, under $40 \mathrm{~mm}$ with $40 \mathrm{~mm}$ and over $\left(\chi_{\mathrm{y}}^{2}=4.773 ; \mathrm{p}<0.05\right)$, and under $50 \mathrm{~mm}$ with $50 \mathrm{~mm}$ and over $\left(\chi_{y}^{2}=4.095\right.$; $\mathrm{p}<0 \cdot 05$ ).
Table 5 shows that the mean pain score falls highly significantly by six weeks to three months in those patients who did not develop PHN but stayed high in those who did (paired $t$ tests). The presence of pain at two weeks to one month was not associated with the development of PHN $\left.\left(\chi_{y}^{2}=0\right) \cdot 148 ; p>0.5\right)$ but the presence of pain at six weeks to three months was, and this highly significantly $\left(\chi_{y}^{2}=8 \cdot 680 ; p<0 \cdot 01\right)$.

\section{Discussion}

Frequency of infection increased with age until 70 and decreased thereafter, but with population correction there was a steady rise in incidence (Fig. 1), conforming with previous work. ${ }^{13 \times 1}$ No cases were seen below age 20, supporting the similar findings of Burgoon et al.' and deMoragas and Kierland. ' However, Edgerton' found several reports of ophthalmic zoster in infancy and concluded that there are two periods in life in which infection is most likely-under 14 and over 40 . It is possible that some affected infants may have been referred elsewhere during our study, explaining the lack of young cases. However, it is certain that infantile ophthalmic zoster is uncommon in the healthy population. The mechanism of infection in this age group is usually exposure to varicella zoster virus in utero at the time of maternal chickenpox."'

Of the 71 patients $63.4 \%$ were female, and this is consistent with previous reports. ${ }^{15}$ However, our age distribution analysis shows that under age 60 there is a highly significant increase in the number of males involved, while female cases were more likely among patients aged 60 and over.

Ocular complications seen in herpes zoster ophthalmicus have been well documented ${ }^{+5 \times 11-1 .}$ and occurred in $50 \%$ of our patients. Anterior uveitis was

Table 5 Mean VAS scores at presentation and subsequent time bands compared with subsequent onset of PHN

\begin{tabular}{|c|c|c|c|}
\hline PHN & Presentation & $2 / 52-1 / 12$ & $6 / 52-3 / 12$ \\
\hline+ & $47 \cdot 42$ & $\begin{array}{r}38.75 \\
p>0.10\end{array}$ & $\begin{array}{r}34 \cdot 5() \\
p>() \cdot 10\end{array}$ \\
\hline- & $34 \cdot 80$ & $\begin{array}{r}23 \cdot 14 \\
p>0 .(05\end{array}$ & $\begin{array}{c}10 \cdot 67 \\
p<0 \cdot(x) 1\end{array}$ \\
\hline
\end{tabular}


commonest, occurring in $92 \%$ of patients with ocular involvement, followed by corneal complications in $52 \%$. These two accounted for the great majority, and all but two cases of corneal disease were associated with an underlying uveitis. Disciform keratitis occurred in $25 \%$ of involved eyes and is approximately twice the incidence reported by Leisegang and Marsh." I:

Ocular motor palsies occurred in two patients and have been reported previously. ${ }^{\times 16} 17$ Most series report a lower incidence, but Marsh et al. ${ }^{17}$ found a much higher $31 \%$ of new cases after careful examination, with several being contralateral or bilateral and third nerve involvement the commonest. As is typical, both our cases resolved spontaneously and completely.

One patient developed orbital apex syndrome seven weeks after the onset of the rash, with combined external ophthalmoplegia, proptosis, and ptosis. Treatment with indomethacin was begun, with a rapid improvement in orbital signs, but three months later the disc was atrophic and the best vision was $6 / 36$. Marsh" ${ }^{11719}$ suggested the use of systemic steroids in these cases in order to reduce the occlusive vasculitis which is the probable underlying mechanism.

Ocular complications not seen in our series but reported elsewhere include nodular episcleritis and scleritis, third nerve palsies, and several corneal manifestations including mucous plaque keratitis, nummular keratitis, perforation, and interstitial keratitis. ${ }^{+5 \mid 1121 \times 211}$

The development of ocular complications was not related to age, sex, or severity of rash but did occur about one week later in the patients aged 60 and over. Nasociliary nerve involvement at presentation was strongly associated with subsequent development of ocular complications $(76 \cdot 2 \%)$, as was the converse. This has been suggested previously" but never subjected to statistical analysis.

Rash severity was not related to age, but duration of rash was significantly shorter in younger patients, especially under 40 .

Much emphasis has been placed in the past on detailed and thorough investigation of all new cases for underlying malignant disease, especially lymphomas. ${ }^{3}$ Recent work has indicated the futility of this by showing that no previously undiagnosed malignancy is likely to be found at onset ${ }^{21}$ and that on long term follow-up the annual incidence of new malignant lesions is similar to that in the normal population."- Our series lends support to this, as no cases of malignant disease were noted at any stage.

Acute pain associated with herpes zoster ophthalmicus is distinct from the later development of postherpetic neuralgia. This study shows that acute pain as measured by VAS decreases with time, and this more rapidly in younger age groups. It is common at presentation, occurring in $82.1 \%$ of patients. Of those who were pain free at presentation $60 \%$ subsequently developed pain. It is therefore apparent that the great majority experience pain at some time.

The incidence of PHN in this study was $21.4 \%$. This is much higher than the $7 \%$ reported by Marsh $^{1119}$ and the $9 \cdot 7 \%$ reported by Burgoon et al. ' It is more in keeping with the higher incidence reported by deMoragas and Kierland. ${ }^{3}$ The development of PHN in one patient aged 25 indicates that, though less common, this is an important complication in younger patients. One patient had no pain until the onset of PHN at six months; one should not assume that the absence of acute pain implies the eventual freedom from PHN.

This study shows that patients aged 80 and over have a significantly higher chance of developing PHN than younger patients. A high VAS pain score at presentation in patients aged 60 and over was significantly associated with PHN. Analysis suggests that a high index of suspicion should be given to presentation scores in excess of $35 \mathrm{~mm}$. There was a very highly significant fall in VAS scores by six weeks to three months in those who did not develop PHN, while for those who did the scores stayed high. Furthermore the presence of pain in this time band was highly significantly associated with PHN.

No association was found between PHN and ocular involvement, chronic eye disease, duration or severity of rash, sex, or nasociliary nerve involvement at presentation.

This study shows that PHN is more likely in older patients and in those who score their pain highly on VAS at presentation. These two factors therefore allow some measure of prediction of which patients should be treated. As our and other work has shown this should be early, preferably before 14 days. Furthermore the failure of VAS scores to fall as the condition progresses should alert the clinician to the impending development of PHN, one of the most severe complications of this disease.

We thank the consultant staff of St Paul's Eyc Hospital and Manchester Royal Eye Hospital for allowing us to study their paticnts and Mrs D Kinsclla for secretarial work.

\section{References}

1 Burgoon CF, Burgoon JS, Baldridge GD. The natural history of herpes zoster JAMA 1957; 164: 265-9.

2 Edgerton AE. Herpes zoster ophthalmicus. Arch Ophthalmol 1945: 93: 40-153.

3 deMoragas JM, Kicrland RR. The outcome of patients with herpes zoster ophthalmicus. Arch Dermatol 1957: 75: 193-6.

4 Lciscgang TJ. Corncal complications from herpes zoster ophthalmicus. Ophthalmology (Rochester) 1985: 92: 316-24. 
5 Womack LW, Lciscgang TJ. Complications of herpes zoster ophthalmicus. Arch Ophthalmol 1983; 101: 42-5.

6 Revill SI, Robinson JO, Rosen M, Hogg MIJ. The reliability of a lincar analogue for cvaluating pain. Anaesthesia 197b; 31: 1191-8.

7 Harding SP, Lipton JR, Wclls JCD, Campbcll JA. Relicf of acutc pain in herpes zoster ophthalmicus by stellate ganglion blockade. Br Med J 1986; 292: 1428.

8 Scheic HG. Herpes zoster ophthalmicus. Trans Ophthalmol Soc UK 1970; 90: 899-937.

9 Juel-Jenson BE. Herpes simplex and zoster. Br Med J 1973; i: 406-10.

10 Bruncll PA, Kotchmar GS. Zoster in infancy: failure to maintain virus latency following intrauterine infection. J Pediatr 1981; 98: 71-3.

11 Marsh RJ. Ophthalmic herpes zoster. In: Darrell RW, ed. Viral Diseases of the eye. Philadelpha: Lea and Febiger, 1984: 78-89.

12 Marsh RJ. Herpes zoster keratitis. Trans Ophthalmol Soc UK 1973; 93: 181-92.

13 Mondino BJ. Corneal manifestations of herpes zoster. In: Darrcll RW, cd. Viral Diseases of the eye. Philadelphia: Lea and Febiger, 1984: 90-6.
14 Pavan-Langston D. McCullcy JP. Herpes zoster dendritic kcratitis. Arch Ophthalmol 1973; 89: 25-9.

15 Kritzinger EE. Long term morbidity of herpes zoster ophthalmicus. Br Med J 1981: 283: 1298-9.

16 Grimson BS, Glaster JS. Isolated trochlear nerve palsics in herpes zoster ophthalmicus. Arch Ophthalmol 1978: 96: 1233.

17 Marsh RJ, Dullcy B, Kclly V. Extcrnal ocular motor palsics in ophthalmic zoster (a revicw). BrJ Ophthalmol 1977; 61: 677-82.

18. Kattah JC. Kennerdell JS. Orbital apex syndrome secondary to herpes zoster ophthalmicus. Am J Ophthalmol 1978: 85: 378-81.

19 Marsh RJ. Current management of ophthalmic herpes zoster. Trans Ophthalmol Soc UK 1976; 96: 334-7.

20 Olsen RJ. Herpes zoster. In: Olsen RJ, ed. Common corncal problems. Int Ophthalmol Clin 1984; 24: 39-48.

21 Lightman S, Marsh RJ, Powell D. Herpes zoster ophthalmicus: a medical revicw. Br J Ophthalmol 1981; 65: 539-41.

22 Ragozzino MW, Melton LJ, Kurland LT, et al. Risk of cancer after herpes zoster: a population study. N Engl J Med 1982; 307: 393.

Accepted for publication 15 July 1986. 